\section{O anti-Durkbeim: por uma análise culturalista do suicídio}

\section{The anti-Durkheim: for a culturalist analysis of suicide}

BARBAGLI, Marzio. O suicídio no Ocidente e no Oriente. Petrópolis: Vozes, 2019.

\section{Gabriel Peters (1)}

(D) https://orcid.org/0000-0002-0595-2663

(1) Professor do Departamento de Sociologia da Universidade Federal de Pernambuco (UFPE), Pernambuco, PE, Brasil. E-mail: gabrielpeters@hotmail.com

DOI: $10.1590 / 3510419 / 20$

Embora as falhas do clássico estudo de Durkheim sobre o suicídio já tenham sido objeto de vasta literatura em nossa disciplina, os motivos pelos quais sociólogos ao redor do mundo continuam a retornar às teses durkheimianas acerca deste desconcertante fenômeno não são muito distintos, creio eu, daqueles que impeliram o autor francês a escrever seu genial livro mais de cem anos atrás. Por um lado, mesmo que rejeitemos o recurso de Durkheim à linguagem biologizante do "normal" e do "patológico", não há dúvida de que ainda tomamos taxas coletivas de suicídio como indícios do quão satisfatória ou insatisfatória, gratificante ou frustrante, tolerável ou intolerável encontra-se a vida dos indivíduos em diferentes contextos societários, estejamos tratando de sociedades in toto (como a União Soviética nos tempos de Stálin) ou de condiçôes existenciais internas a uma sociedade (relativas a classe, gênero, raça, sexualidade, religiosidade, estado civil etc.). Por outro lado, dirigir o foco sociológico para um ato que parece individual e privado em grau máximo (portanto, supostamente fora da alçada da sociologia) permanece uma tentação para os interessados em demonstrar a potência explicativa dessa disciplina, bem como sua relevância em questóes - literalmente - de vida ou morte.

Uma aproximação didática ao alentado estudo de Marzio Barbagli sobre O suicídio no Ocidente e no
Oriente, que acaba de aparecer em tradução brasileira, sem a alusão do título original ao "retirar-se" ou "despedir-se" do mundo (Congedarsi dal mondo: Il suicídio in Occidente e in Oriente, 2010), consiste em tomá-lo como uma revisão crítica da suicidologia de Durkheim a partir de uma perspectiva mais atenta à enorme variedade histórica e cultural das causas de suicídio. Se a moldura positivista da investigação durkheimiana, com sua busca de generalizaçóes monocausais (nas conexóes entre [des] integração social e suicídio egoísta, ou entre [des] regulaçáo social e suicídio anômico, por exemplo), já foi amplamente criticada em debates teóricos, Barbagli realiza uma crítica in actu dos tropeços generalizantes de Durkheim ao mostrar a quantidade abrangente de material histórico que refuta suas supostas leis sociológicas sobre o suicídio. Ainda que o autor italiano se ancore em uma orientação historiográfica para criticar as generalizaçóes sociológicas de Durkheim, o alcance espaço-temporal de sua pesquisa se aproxima mais das grandiosíssimas ambiçóes de certa sociologia histórico-comparativa do que dos recortes mais circunscritos da historiografia especializada. Barbagli percorre nada menos do que o arco histórico de um milênio que vai da Idade Média até o século XX, tanto no Ocidente (na verdade, sobretudo na Europa) quanto no Oriente (sobretudo na Índia e na China, com incursóes ligeiras ao Oriente Médio). Ele não se furta, é claro, a admitir a pobreza de dados empíricos confiáveis sobre as taxas de suicídio na história europeia anterior ao século XIX, ou em sociedades do Oriente até os primórdios do século XX, mas faz um esforço admirável para encontrar, coligir e organizar quaisquer farelos de informação documental relevante nestes cenários histórico-geográficos.

Entrecruzando dados quantitativos e qualitativos, Barbagli combina um olhar macroscópico sobre transformaçôes sócio-históricas, lastreado em um vasto acervo de estatísticas, a um rico repertório de microanedotas acerca de uma miríade impressionante de casos particulares de suicídio. Se vários desses exemplos de atos suicidas tendem, pela própria natureza, a impactar com força a sensibilidade do leitor, vale lembrar que a prosa do autor é deliberadamente expurgada, com frieza digna da clínica forense, de qualquer pathos. Ao trazer sua perspectiva - multicausal 
e mais sensível à diversidade histórico-cultural - à problemática durkheimiana, o sociólogo italiano não nega a existência de regularidades empíricas no que toca ao ato suicida. Tampouco supóe que fatores sociais no sentido amplo, incluindo-se aí crenças e valores culturais, não influenciariam a produção de mortes voluntárias. A sensibilidade histórico-cultural mobilizada aqui procura mostrar, em vez disso, como os laços causais entre suicídio e sociedade são bem mais complexos e multifacetados do que supunham as tipologias monocausais da obra durkheimiana. De resto, se a riqueza de dados estatísticos e eventos históricos discutidos por Barbagli dá testemunho dos limites da teorização generalizante frente à diversidade empírica da vida social e da experiência individual, o sociólogo italiano não deixa de esposar uma pretensão teórico-analítica mais ampla: superar as limitações do enfoque sócio-estrutural de Durkheim mediante uma orientação predominantemente culturalista de exame do suicídio. Sem fazer vista grossa a fatores como integração e regulação social na intelecção do fenômeno, Barbagli quer demonstrar que mesmo a influência destes fatores é mediada por crenças, normas, rituais e esquemas interpretativos que a cultura oferece aos indivíduos como orientaçóes de conduta (pp.16 e 59).

Durkheim valeu-se de expedientes engenhosos para sustentar a tese, profundamente contra-intuitiva, de que as intençôes com base nas quais os indivíduos tiram a própria vida podem ser negligenciadas pela análise sociológica. Rejeitar essa tese durkheimiana, como faz Barbagli com bom senso (p.14), não significa, digamos de novo, negar a importância de fatores sociais (lato sensu) na produção de suicídios. Ao contrário, o autor mostra que aquelas intenções só podem ser compreendidas em termos de molduras culturais particulares, uma vez que as motivaçóes de uma conduta táo extrema estão entrelaçadas a maneiras culturalmente variáveis de dar significado a si, aos outros e ao mundo (p.18). Por exemplo, mesmo as emoções mais viscerais associadas ao suicídio, como um sentimento insuportável de humilhação social, são mediadas por esquemas cognitivos e avaliativos que os agentes interiorizam de suas culturas, e que são discrepantes daqueles vigentes em outras. Assim, um evento tomado como insuportavelmente desonroso em um contexto sociocultural (uma derrota militar, digamos) pode não sê-lo em outro, e vice-versa. De maneira mais geral, tais repertórios culturais variáveis de crenças e normas são decisivos para a explicação sociológica do suicídio, na medida em que dão respostas distintas às motivaçóes suicidas (tentação do demônio, temperamento melancólico, desequilíbrio neuroquímico), à (i)moralidade do ato em si (invariavelmente condenável, um direito individual inalienável de decisão sobre a própria vida, arma legítima de protesto moral ou de ataque a um inimigo) e, finalmente, às vias de ação disponíveis para aqueles que são afligidos por humores suicidas (recolher-se a um mosteiro, tomar medicamentos antidepressivos, martirizar-se em nome de uma causa). ${ }^{\mathrm{i}}$

Perfazendo o caminho de longuíssima duração que vai da Idade Média até o século XX na Europa, o capítulo 1 explica o aumento na incidência de suicídios no continente entre os séculos XVII e XIX com base, sobretudo, no enfraquecimento do repertório cultural de crenças e normas pelo qual, nos séculos anteriores, a morte voluntária havia sido percebida, avaliada e socialmente manejada (os rituais funerários realizados, o destino dado aos bens do suicida, etc.). A severidade com que o suicídio foi tratado pela cosmologia cristã medieval atuara como uma poderosa barreira psicocultural ao atentado contra a própria vida (pp. 60-100), ao passo que o aumento no número de suicídios a partir do século XVII foi possibilitado pelo desenvolvimento de visóes de mundo bem mais tolerantes em relação ao ato suicida, como a defesa da autonomia individual e "a tendência de atribuir importância crescente à busca do prazer pessoal terreno, aqui e agora, e não mais no além” (p. 110). Os esquemas interpretativos de matriz cristã que, ao longo de mais de mil anos, atuaram como diques muito firmes (ainda que não infalíveis) contra o suicídio entre os indivíduos socializados naquela visão de mundo assumiram forma sistematizada em pensadores como Agostinho (pp. 60-65) e Tomás de Aquino (pp. 66-67). Para além dessas sistematizaçôes eruditas, contudo, a condenação cristã do suicídio logrou penetrar a consciência de um alto número de fiéis "comuns" na Idade Média, para os quais o suicídio, como um "auto-homicídio", não apenas violava o interdito bíblico ao assassinato 
como também diferia do assassinato de outrem por impedir a possibilidade de expiação terrena do pecado.

A ética do cristianismo medieval acerca da morte voluntária discrepava fortemente, desnecessário dizer, daquela que vigorara na Antiga Roma (p. 60), o que é indicado por tantos exemplos de "suicídios heroicos" celebrados como atos nobres de liberdade por figuras da Antiguidade, como o estoico Catão. No mais, como convinha a uma cosmologia religiosa, a etiologia do suicídio entre os cristãos da Idade Média não o retraçava ao que hoje chamaríamos de causas estritamente psicológicas, mas "introduzia fatores sobrenaturais... em cada elo da cadeia explicativa” (p. 77). A crença de que pensamentos, afecçóes e, finalmente, açóes suicidas eram suscitadas pelo demônio para afastar, assim, os indivíduos da graça divina era partilhada por católicos com os doutrinadores da Reforma Protestante, como Lutero e Calvino (pp. 80; 98). Ao ser interiorizada pelos habitantes cristãos da Europa medieval, a ideia de que sucumbir aos impulsos suicidas significava entregar-se às tentaçóes mesmas do diabo, condenando a própria alma ao inferno eterno, servia de barreira ao "auto-assassinato". Tais "controles internos" não deixavam de ser reforçados por uma série de "controles externos" (p. 97). A severíssima condenação do suicídio, partilhada por autoridades civis e religiosas com a população em geral, traduzia-se, por exemplo, em todo um conjunto de rituais de profanação (pp. 49-59) dos (supostos) suicidas, dirigidos aos seus corpos (encharcá-los de lama, pendurá-los de cabeça para baixo em lugares expostos à visitação pública), assim como a seus bens (destruir suas casas, queimar seus campos).

Fustigando, mais uma vez, uma tese durkheimiana, Barbagli mostra, no capítulo 2, que tendências modernas, como "o desenvolvimento dos direitos do indivíduo diante do Estado" e a "concepção da pessoa humana como coisa sagrada” (p. 101), levaram não à intensificação da reprovação moral do suicídio, mas, ao contrário, a uma crescente tolerância em relação à morte voluntária. Com o avanço da modernidade, explicaçôes sobrenaturais do suicídio como uma tentação demoníaca foram substituídas, cada vez mais, por uma psicologia médica dos humores que conferia destaque a uma noção multidimensional de melancolia, "ampla... a ponto de abranger o que hoje chamamos de distúrbios de ansiedade, de humor, de personalidade, bem como incontáveis formas de fobia, alucinação e delírios" (p. 123). Da mesma maneira que procedera com pensadores medievais, Barbagli toma as formulaçóes de autores como Montaigne, Donne, Shakespeare, Hume, Montesquieu, Voltaire e Beccaria como representativas de uma mudança significativa na sensibilidade ética quanto ao suicídio exibida pelos europeus entre os séculos XVI e XIX (p. 117). O próprio termo "suicídio", oriundo de um neologismo em latim cunhado por Thomas Browne em 1642, refletia uma necessidade de diferenciá-lo com mais veemência do homicídio, diferenciação para a qual as referências de outrora ao "auto-assassinato" (self-slaughter, em Shakespeare, e homicide de soy-mesme, em Montaigne) tornaram-se insuficientes. Pioneiro da sensibilidade moderna - neste como em tantos outros aspectos -, Montaigne afirmou, por exemplo, que chamar de homicida alguém que tira a própria vida seria tão inadequado quanto chamar de ladrão quem retira os próprios pertences da bolsa (p.146).

No terceiro capítulo do livro (pp. 148-177), Barbagli sustenta que, entre os séculos XVI e XIX, as taxas de homicídio nos países europeus tenderam a cair, enquanto seus índices de suicídio aumentaram. $\mathrm{O}$ autor questiona as explicaçóes desses "andamentos opostos" (p.149) que recorrem a "uma concepção hidráulica da ação humana” (p.155), explicaçóes para as quais as pulsões violentas que os indivíduos não podiam mais extravasar pelo homicídio, devido à intensificação dos "controles civilizadores" (Elias) sobre seus impulsos, terminavam por ser autodirigidas. Sem abandonar sua consciência quanto a "diversas mudanças ocorridas na Europa, em grande parte independentes entre si”, o sociólogo italiano aponta de novo para uma transformação ética na sensibilidade cultural: "Antes de mais nada, mudou radicalmente a avaliação moral dessas duas açóes, e passou-se a adotar uma severidade muito maior frente ao homicídio do que... ao suicídio" (p.163). O capítulo 4 é mais eclético em seus propósitos. Ele abriga, por um lado, uma investigação de como os índices de suicídio foram impactados por alguns dos processos que mais profundamente afetaram a Europa do século de 1900, como a perseguição genocida aos judeus em um continente tomado pelos nazistas (pp. 
183-201), as duas guerras mundiais (pp. 202-213), os efeitos do regime soviético na Europa Oriental (pp. 247-258) e o desenvolvimento de tratamentos medicamentosos para dores crônicas e sofrimentos psíquicos (pp. 243-247). Por outro lado, Barbabli também revisita algumas variáveis sociológicas consideradas comumente na análise do suicídio no Ocidente desde Durkheim e seus contemporâneos, como religiâo (pp. 180-183), nacionalidade (pp. 213-217), raça (pp. 217-224), gênero (pp. 224-229) e orientação sexual (pp. 229-233). Sempre misturando particularização anedótica e generalizaçóes estatísticas, o texto alcança aqui uma densidade de informação que desafia imensamente qualquer tentativa de resumi-lo. ${ }^{\text {ii }}$

O capítulo 5 abre a segunda parte do livro, voltada a aspectos do suicídio no "Oriente". Barbagli se embrenha em uma análise histórica do sati, ritual indiano em que mulheres cujos maridos faleceram cometem suicídio (por exemplo, lançando-se, normalmente diante de expectadores, na mesma pira em que o corpo do esposo é cremado). Previsivelmente, o autor rejeita uma explicação dessa forma de suicídio em termos da dissolução mais ou menos completa do indivíduo na coletividade, notando que, "quanto mais se recua no tempo (em direção a uma sociedade mais 'primitiva' e com um maior grau de subordinação do indivíduo ao grupo), tanto menor é a importância do sati" (p. 277). O fator crucial em tais mudanças segundo a perspectiva barbagliana, como já sabemos a essa altura do campeonato, é o conjunto de esquemas culturais pelos quais são percebidos, avaliados e, por conseguinte, vivenciados emocionalmente os fenômenos implicados nesse ritual, como a viuvez e a morte voluntária. Em função de tais esquemas, a opçâo do sati tendeu a emergir, com frequência, como alternativa preferível a todo um conjunto de estigmatizaçóes sociais que tornavam terrivelmente difícil a vida das viúvas naquelas sociedades indianas (p. 294).

O capítulo 6 lida com traços culturais que singularizam o suicídio na sociedade chinesa em comparação com diversos outros contextos nacionais ao redor do mundo, como a maior taxa de suicídios entre mulheres do que entre homens, e a ocorrência mais frequente no campo do que nas cidades (pp. 307-309). Nesse capítulo, Barbagli trata em pormenor de uma forma de suicídio não tematizada por Durkheim, que tendeu a parecer bizarra e ininteligível para os repertórios culturais do Ocidente Europeu, embora tenha aparecido frequentemente na China e em uma variedade de cenários não ocidentais: o suicídio como ato de agressáo dirigido a outras pessoas, como protesto e/ou vingança frente a alguma ação cometida por elas; uma forma de "acusação pública" que poderia gerar "custos morais e econômicos altíssimos para quem fosse apontado como responsável” (p. 350) (provocando remorso, vergonha, culpa ou ataques à sua reputação, por exemplo). De novo questionando deduções apressadas sobre a subordinação do indivíduo ao grupo no Oriente, o autor demonstra, por exemplo, que, na sociedade chinesa, os suicídios das "viúvas fiéis" (pp. 324-328) que se recusam a sobreviver aos maridos, comumente considerados casos de suicídio altruísta induzidos pelo conformismo social, são frequentemente o contrário disso: ações de resistência individual à intensa pressão das famílias para que se casem novamente (pp. 319; 325; 327; 413).

Finalmente, ainda na seara do suicídio qua agressão, Barbagli se volta, no capítulo 7 , ao suicídio como arma de luta, um ato pelo qual procura-se provocar a morte de outras pessoas em nome de alguma causa política e/ou religiosa. Já presente nas ações militares dos kamikazes japoneses na Segunda Guerra Mundial, a prática se espalhou rapidamente por diversos cenários do mundo a partir dos anos 1980, quando passou a ser utilizada no Sri Lanka, pelos Tigres do Tâmil, e pelo Hezbollah, no Líbano (p. 376). Ao discutir os usos do "corpo como bomba" (pp. 363-405), o sociólogo italiano corrige um conjunto de suposiçóes frequentes a respeito do fenômeno, como a ideia de que tais usos se concentrariam sobretudo entre fundamentalistas islâmicos: "A análise das missóes suicidas em todo o mundo de 1983 a 2003 evidenciou que metade ou mais da metade delas foi... lançada por organizaçóes laicas" (p. 378). Considerando que "as organizações terroristas agem habitualmente com a racionalidade de uma empresa econômica” (p. 375) no que toca aos meios que usam para atingir seus fins, Barbagli sublinha que a complexidade operacional dos atentados suicidas tende a requerer participantes "instruídos" e "especializados" (Ibid.). Sua realidade é bem mais complexa, portanto, do que sugeririam contrastes 
simplistas entre um Ocidente "avançado" e um Oriente "primitivo": longe de se reduzir a expressóes de um "tribalismo" fanático, oriundo de comunidades fechadas à presença do moderno, muitas missóes suicidas são levadas a cabo por indivíduos com alto nível de instrução formal e traços ostensivamente "cosmopolitas", como a experiência de circulação por diversos países e o conhecimento de variados idiomas (pp. 385-386; 414).

Como diagnóstico histórico-sociológico, o que fica, afinal, do livro de Durkheim alvejado por Barbagli? O estudo durkheimiano pressupôs que as taxas de suicídio egoísta aumentariam conforme diminuiria o nível de integração social, ao passo que graus altos de integração social corresponderiam a taxas mais altas de suicídio do tipo altruísta. No fim das contas, Barbagli ataca a visão durkheimiana pelos dois flancos, ao mostrar tanto a presença frequente de suicídios egoístas em sociedades "pré-modernas" ou não modernas quanto uma escalada de suicídios altruístas em cenários modernos ao longo do século XX. Por um lado, na medida em que envolvem a renúncia à própria vida em prol de uma causa política e/ou religiosa de grupo, os ataques suicidas que proliferaram no mundo desde o início da década de 1980 ilustram formas de suicídio com componente "altruísta" (em sentido durkheimiano técnico) que vicejam em circunstâncias altamente modernizadas. Por outro lado, ao longo das últimas décadas do século XX, as sociedades da Europa Ocidental foram palco de um decréscimo muito significativo nas taxas de suicídio egoísta e anômico, a despeito de uma radicalizaçâo nas tendências históricas às quais Durkheim atribuíra o incremento daquelas taxas no século XIX. No quesito "integração", vínculos sociais tradicionais (família, casamento, comunidades religiosas, sindicatos, associaçóes voluntárias, partidos políticos) se tornaram ainda mais frouxos ou "líquidos" (Bauman) em uma modernidade tardia que tem na individualização um de seus principais vetores históricos. No quesito "regulação", longe de exigir dos indivíduos um controle mais estrito de seus desejos, a fase tardia da modernidade, marcada que é por um capitalismo tecnologicamente saturado de imagens e fantasias, mais parece exortar os indivíduos à realização de desejos múltiplos e intensificados. Se nenhum fortalecimento da integração e da regulação explica, portanto, tal queda nas taxas de suicídio, como explicá-la? Sem abandonar sua ciência de uma pluralidade de causas, Barbagli confere um papel de proa aos tratamentos médicos e farmacológicos de dores crônicas e sofrimentos psíquicos na segunda metade do século XX. Sublinhando corretamente a importância de compreensóes e abordagens "medicalizantes" da depressão e de "ideaçôes suicidas" na queda das taxas de morte voluntária, Barbagli poderia ter acrescentado que tais desenvolvimentos farmacológicos não devem ser considerados isoladamente, mas como parte de todo um conjunto de dispositivos socialmente disponiveis de atenção e tratamento de transtornos com potencial suicidógeno, que incluem desde a psicoterapia até os centros de prevenção e grupos de apoio.

Pelo menos ao escriba dessa resenha, a densidade de informaçôes histórico-sociológicas do livro provoca, ao final da sua leitura, um senso de vertigem, como se a lição principal a extrair desse tour de force fosse a consciência perplexa de que são imensamente variáveis as motivaçóes e os contextos nos quais seres humanos tiram a própria vida. De resto, como costuma acontecer em obras com objetos tão grandiosos, este texto devotado ao suicídio no "Ocidente e no Oriente" termina chamando atenção para suas gigantescas lacunas, como a parquíssima exploração do suicídio em sociedades da América Latina e África, que permanecem à espera de um livro igualmente ambicioso. A riqueza de informaçôes do livro de Barbagli também cobra seu preço, finalmente, na forma de déficits analíticos no tratamento de outras perspectivas teóricas e empíricas, o que se reflete na maneira en passant, rápida e quase preguiçosa como menciona e descarta argumentos complexos que mereceriam ser tratados com mais esmero, como a teoria eliasiana dos processos civilizadores (pp. 174-176) ou a explicação durkheimiana das taxas de suicídio diferentes entre católicos e luteranos (pp. 181-182). No fim das contas, é testemunho da complexidade do fenômeno do suicídio que mesmo um livro enciclopédico como o de Barbagli esteja longe de dissolver o que há de mistério neste que é um dos mais intrigantes atos humanos. 


\section{Notas}

i Em uma das melhores análises críticas da obra durkheimiana, que antecipa Barbagli em sua crítica a uma orientação monocausal e em sua defesa de um enfoque sobre causas culturais, Hamlin e Brym (2006, p. 44) sublinham que o privilégio explicativo que Durkheim confere a fatores sócio-estruturais, em detrimento da dimensão cultural, não vale para a sua obra como um todo, mas sobretudo para seus estudos da década de 1890, que contrastam com o enfoque explicativo culturalista de As formas elementares da vida religiosa.

ii Uma sensibilidade multicausal na sociologia dos suicídios tem de atinar com o fato de que os fatores plurais envolvidos na produção de mortes voluntárias podem não apenas se favorecer entre si, mas também contrabalançar uns aos outros de modos historicamente contingentes. Isto é evidenciado, por exemplo, pela queda nos índices de suicídio entre ingleses no intervalo entre 1964 e 1975, período em que aumentaram, em contrapartida, as taxas de divórcio, criminalidade e desemprego. Um fator primordial nessa queda consistiu simplesmente na substituição crescente, nos lares ingleses, do gás derivado de carvão, com alta quantidade de monóxido de carbono, pelo gás natural, bem menos tóxico. Em contraste com a condição anterior, na qual um gás muito tóxico estava disponível em quase todas as casas, era de fácil uso e gerava uma morte indolor (que, de resto, não desfigurava o rosto e o corpo), muitos indivíduos, "não podendo servir-se de gás", "renunciaram ao suicídio", de modo tal que "o número total das mortes sofreu uma grande queda” (p. 236). A queda nos suicídios indicava, nesse caso, um princípio mais geral: a maior ou menor disponibilidade contextual de meios de suicídio (armas de fogo, por exemplo) é, em muitos casos, a diferença na passagem da ideaçáo suicida ao ato propriamente dito.

\section{Referências}

HAMLIN, Cynthia; BRYM, Bob. (2006), “The Return of the Native: A Cultural and Socio-Psychological Critique of Durkheim's Suicide based on the Guarani-Kaiowá of South-Western Brazil". Sociological Theory, v. 24, n. 1, pp. 42-57. [https://journals.sagepub.com/doi/ pdf/10.1111/j.0735-2751.2006.00263.x] 